\title{
Partner support reduced depressive symptoms in postpartum depression
}

Misri S, Kostaras X, Fox D, et al. The impact of partner support in the treatment of postpartum depression. Can J

Psychiatry 2000 Aug;45:554-8.

\section{QUESTION: In women who receive treatment for postpartum depression (PPD), does encouraging partner support reduce depressive symptoms?}

\section{Design}

Randomised \{allocation concealed*\}†, unblinded*, controlled trial with 10 weeks of follow up.

\section{Setting}

2 major university hospitals in Vancouver, British Columbia, Canada.

\section{Patients}

29 women (mean age 33 y) with $D S M-I V$ criteria for major depression with postpartum onset and an Edinburgh Postnatal Depression Scale (EPDS) score of $\geqslant 12$. All women were married or cohabiting. Follow up was complete.

\section{Intervention}

16 patients were allocated to the support group and 13 to the control group. The patients in both groups attended 7 psychoeducational visits. In the support group, partners also participated in 4 of the 7 sessions where positive interaction between the couple was encouraged by focusing specifically on postpartum issues such as helping with the baby and participation in house work.

\section{Main outcome measures}

Scores for patients on the EPDS, Kellner Symptom Questionnaire, Dyadic Adjustment Scale (DAS), Parental Bonding Instrument, and depression status established by the Mini International Neuropsychiatric Instrument (MINI). Scores for partners on the DAS and the General Health Questionnaire (GHQ-12).

\section{Main results}

At 10 weeks of follow up, fewer patients in the support group were classified as having major depression (using the MINI) than were those in the control group (table). Also, mean scores were lower on the Kellner and EPDS, indicating less distress and fewer depressive symptoms, respectively, for patients in the support group (table). For partners at 10 weeks of follow up, mean scores on the GHQ-12 were lower in the support group indicating less psychological distress (table). No other statistically significant differences existed between the groups.

\section{Conclusion}

In women with postpartum depression, encouragement of partner support reduced depressive symptoms in women and psychological distress in their partners.
*See glossary.

$\dagger$ Information provided by the author.
Source of funding: no

For correspondence: Dr S Misri,

Reproductive Mental Health Program, St Paul's Hospital, 2B-250 1081 Burrard Street, Vancouver, $B C$ V6Z 1 Y6, Canada. Fax +16048068621 . external funding.

Partner support $v$ control group for women with postpartum depression at 10 weeks of follow $u p \ddagger$

\begin{tabular}{lllll} 
Outcome & Support & Control & RRR (95\% CI) & NNT (CI) \\
MINI: Major depression & $19 \%$ & $62 \%$ & $70 \%(17$ to 90$)$ & 3 (2 to 15) \\
\hline Outcomes & Support & Control & Mean difference (CI) & p Value \\
Mean score on EPDS & 8.6 & 14.7 & $6.1(1.4$ to 10.8$)$ & 0.01 \\
\hline Mean score on Kellner & 2.1 & 6.6 & $4.5(0.7$ to 8.3$)$ & 0.02 \\
\hline $\begin{array}{l}\text { Mean score on GHQ-12 } \\
\text { (partner) }\end{array}$ & 18.4 & 43.0 & $24.6(5.7$ to 43.5) & 0.01 \\
\hline $\begin{array}{l}\text { FMINI=Mini International } \\
\text { GHQ=General Health Questionnaire. Other abbreviations defined in glossary; RRR, NNT, Cl, and mean differ- }\end{array}$
\end{tabular}
ence calculated from data in article.

\section{COMMENTARY}

Since PPD is usually conceptualised as a maternal pathology, treatment trials have typically focused on treating the mother. The study by Misri $e t a l$ is a cogent reminder that in PPD, the father's psychological wellbeing may also be affected (specifically, increased GHQ-12 scores among partners in the control group at 10 weeks of follow up). Their finding echoes the earlier report that as many as half of the partners of women with PPD also suffered depression. ${ }^{1}$ Paternal PPD, however, is regularly forgotten in research and clinical practice.

Misri et al show that the price for missing out the father in the treatment process can be costly. This omission delayed maternal recovery and also aggravated the father's psychological health. Rather than formal family therapy, the simple act of inviting the partner to the treatment sessions, and encouraging him to engage with childcare and other household tasks are adequate to improve maternal depression. Besides, if the partner provides better support to expedite the mother's recovery, he avoids becoming distressed, and probably depressed, in the long run.

Given these findings, should we make "psychoeducation on partner support" routine in the management of postnatal depression? A natural response to this question is that we need further studies with larger samples, documentation of improved social support after intervention, and more sophisticated statistical analysis. Yet, one may argue that the suggested measures should be part and parcel of good clinical practice anyway. Thus, even before robust data are available, there is no reason why the partners should not be sensibly involved in the management of PPD.

Finally, as PPD is associated with poor marital relationship, it is common to encounter partners who refuse to participate in any treatment process. Thus, future studies should also examine whether mobilising social support from other family members is equally effective in accelerating recovery from PPD. Dominic Lee, MBChB(Hons), MD, MRCPsych, FHKAM, FHKCPsych The Chinese University of Hong Kong Hong Kong, China, NT

1 Ballard C, Davis R. Postnatal depression in fathers. International Review of Psychiatry 1996;8:65-71. 